here, and by this time a small sore was discovered at the left side of the tip of the nose, just within the nares. The discharge ceased and the swelling decreased and eventually only a small scar was left. In this instance it appeared likely that the infection was conveyed from the infant's arm to the mother's nose through the medium of a pockethandkerchief. - I am, Sirs, yours faithfully,

Blackheath, June 23rd, 1900. WALTER KIDD, M.D. Lond.

\section{"HORSE AMBULANOES."}

To the Editors of THE LANCET.

SIRS,--Perhaps the ancient and loyal borough of Wigan can lay claim to having one of the most complete systems of ambulances of any similar town in the kingdom. When I tell you that there are stationed in the town and district no fewer than 24 horse ambulances and 12 hand-wheel ambulances it will be at once evident that both Wigan and the district are doing their share of the work indicated in The LANCET. But this has been going on for 20 years. The ambulance movement has all along been roiced through the annual report of the Royal Albert Edward Infirmary and through the local press, and there has not been lacking that spirit of magnanimity and generous kindness on the part of friends of this hospital to provide what was needed to establish this excellent hospital corps of which we are justly proud. The medical men in the district have done their share in giving lectures on "first-aid and ambulance work" in the various works, so that within a circle with a radius of nine miles from this hospital you will find men who have profited by those lectures and have possessed themselves of certificates or medals granted for proficiency by the St. John Ambulance Association.

I am, Sirs, yours faithfully, WILLIAM TABERNER, General Superintendent and Secretary, Royal Albert
June 26th, 1900.

\section{MIDWIVES' REGISTRATION.}

\section{To the Editors of THE LANCET.}

Sirs, - The protest published in The LaNCeT of June 16th from the Beckenham and Penge Medical Society regarding the conduct of the Cannon-street Hotel meeting contained in a letter of sympathy to Dr. Glover would not require an answer did it not contain the statement that the delegates of that society went there "prepared to submit some very carefully considered alterations in the Midwives Bill which they hoped might render it a useful measure and one which would safeguard the public and be acceptable to the general practitioner." Of these "carefully considered alterations" we heard nothing either at the preliminary committee meetings or at the meeting itself. And how can this statement be made consistent with this society's delegates (including Mr. Sturges) having composed and signed the following, which is an extract from a letter which accompanied the invitation to the meeting?

It is the opinion of the large majority of medical men, and particularly of general practitioners, who see most and know most of the class of work the Midwives Bill is intended to legislate for, that it is a measure likely to effect incalculable harm. Even if it provided, as it does not, for restricting to natural cases of labour only the legalised attendance of midwives, the harm would not be guarded against, for a natural case of labour requires complete scientific knowledge to diagnose and may become urgent complete scientifc knowledge to diagnose and may become urgent and dangerous at any time between its commencement and completion. Since the study of midwifery has been changed, chiefly owing to the labours of the late Sir James Simpson and the Edinburgh School, from a despised art to an honoured science, the saving of life and suffering has been immense (as statistic will show and the genus Mrs. Gamp, so powerfully exposed by Charles Dickens, has been disappearing by the ordinary process of evolution. That being so, the eril which we all recognise to exist seemed to be gradually curing itself ; but the effects of this legislation, we fear, wil b9 to revive it in a more dangerous form than ever existed before. The Medical Acts, which were drafted in the interests of the public, wisely ordained that medical men who are licensed to practise in any one branch of medicine or surgery (including midwifery) must show a thorough knowledge in all. Going absolutely against this principle the Midwives Bill will give a State-guaranteed qualification to women wh can at most possess the little knowledge that is dangerous, which will deceive the public into thinking that in employing a midwife they are employing a properly qualified person to whom they are justified in entrusting their lives. We feel "ery strongly that this Bill has not been properly considered or the effect it will have sufficiently weighed and although we wish all who follow the calling of nurse to the sick could be properly trained and even certificated by law we are concinced that no measure which prorides for the attendance of lying-in women without proper medical supervision can fail to be productive of a largely inoreased death-rate among women and infants and also do much to encourage criminal practices.

This is the rational and consistent position which we still hold and the one from which they have apparently been washed back by the dogmatic ground-swell of medicopolitical orthodoxy.

I am, Sirs, yours faithfully,

Sydenham, June 17th, $1900 . \quad$ F. LoRrMER HART.

\section{HEALTH AND SANITARY CONDITION OF ABERDEENSHIRE : BRAEMAR SPECIAL DISTRICT.}

\author{
To the Editors of THE LANCET.
}

Sirs,-In the issue of ThE LAxceT of June 9th, 1900, page 1682, under the heading of "Health and Sanitary Condition of Aberdeenshire," at the end of the paragraph it is stated that "scavenging has improved in all the districts except Aboyne, Torphins, and Braemar, 'where nothing has as yet been done." "This statement is incorrect as regards the Braemar district, where a scavenger has been employed for the last three years and paid a regular salary during that time. I have, therefore, to ask you to contradict the latter part of the paragraph in so far as Braemar district is concerned.

I am, Sirs, yours faithfully,

WM. MICHIE,

Clerk to Braemar Special District.

Tullochcoy, Crathie, June 23rd, 190 J.

\section{THE RAILWAY MEDICAL OFFICERS' UNION.}

To the Editors of THE LANCET.

SIRS,--It will be a very great convenience and will considerably aid organisation amongst railway medical officers if you will allow me to ask those who previously communicated with me, as well as those who have not, if they will let me know as soon as possible whether they could attend a meeting at Ipswich during the session of the annual meeting of the British Medical Association, with a view of instituting a union for the protection and promotion of the interests of railway medical officers.

I find that the medical officers of some railway companies are already organised, having had associations for some years. If they will attend the proposed meeting their experience will be of use, not only in assisting the medical officers of other companies to form associations on their respective lines, but also in forming the national unicn.

There is nothing revolutionary intended in the proposed union. The objects are (1) to promote unity and good fellowship; (2) to compare the rates of payment of the different staffs ; (3) to consider whether there should be a separate payment for minor surgical injuries as well as to consider the special fees for fractures, dislocations, \&c. ; (4) to consider the question of gratuitous or paid ambulance lectures ; (5) to consider how we can protect each other from those who are seeking the appointments which we hold; and (6) finally to consider any other means which may be proposed from any member or staff likely to be for our mutiual benefit.

If I hear from a sufficient number of medical officers I will make arrangements for a meeting at Ipswich and shall be glad to know what day and hour during the annual meeting will be most convenient for each writer. I not only wish to hear from those who have made arrangements to go to the annual meeting of the British Medical Association, but those who could make it convenient to run there speciaily for this meeting but have not the time at their disposal to remain for any other meeting. Our meeting will not be restricted to members of the British Medical Association. I shall be glad to hear from those unable to attend a meeting at Ipswich whether they are favourable to the union and will give it cordial support, in all cases stating what company they are attached to and any details connected with their appointment that may be of interest and utility to their colleagues. All communications will be regarded as confidential, facts only being made use of, not the names of the authors.

$$
\text { I am, Sirs, yours faithfully, }
$$

G. H. BROADBEXT,

Medical Offeer G.N. and G.C. Ry. Cos.

8, Ardwick-green, Manchester, June 25th, 1900. 